\title{
Diffuse unresolving pulmonary nodules in a patient with a history of cervical carcinoma
}

\author{
Talal Hilal
}

University of Kentucky, Lexington, Kentucky, USA

\section{Correspondence to \\ Dr Talal Hilal,}

talal.hilal@uky.edu

Accepted 7 March 2015

\section{DESCRIPTION}

A 33-year-old woman with a history of cervical carcinoma status post total abdominal hysterectomy and bilateral slapingo-oopherectomy in 2006 presented to the emergency department with acuteonset, sharp, pleuritic chest pain associated with shortness of breath and fever up to $39.9^{\circ} \mathrm{C}$. Physical examination revealed a patient in severe respiratory distress with a rate of 54 breaths/min, heart rate of $154 \mathrm{bpm}$ and blood pressure of 104/ $64 \mathrm{~mm} \mathrm{Hg}$. She was intubated emergently and placed on mechanical ventilation. Chest auscultation revealed decreased breath sounds and crackles bilaterally. A CT of the chest with intravenous contrast revealed innumerable nodules throughout both lung fields with scattered central necrosis (figure 1A). A blood clot obstructing the inferior vena cava (IVC) was visualised incidentally, and percutaneous extraction was performed. The patient went into septic shock rapidly and empiric broad-spectrum antibiotics were initiated. Blood, sputum and clot cultures grew Gram positive cocci identified as methicillin-resistant Staphylococcus aureaus (MRSA). The clinical picture coupled with the presence of diffuse pulmonary nodules was consistent with a diagnosis of septic pulmonary emboli (SPE) from MRSA seeding the IVC clot.

The patient had multiple complications from the severe inflammatory response over the ensuing month, including acute respiratory distress syndrome and acute kidney injury requiring renal replacement therapy. The acute period was also complicated by multiple pneumothoraces requiring chest tube placement. A repeat CT of the chest on day 30 failed to show significant improvement in size or quantity of pulmonary nodules despite 4 weeks of directed antibiotic therapy (figure 1B). The concern was that the patient may have had these nodules prior to this acute illness and that they may represent metastatic disease from her history of cervical carcinoma. The theory would have explained the IVC clot in a patient without known hypercoagulable disorders. To determine definitively the nature of these nodules, a transthoracic biopsy was undertaken, which showed alveolar lung parenchyma with abundant acute and chronic inflammation, and areas of consolidation and necrosis consistent with focal necrotising pneumonia. There was no evidence of malignancy.

An approach to the differential diagnosis of diffuse pulmonary nodules is described in figure 2 . The present case had lesions of different sizes, some with central necrosis, involving the pleural surfaces, in a random distribution, which made malignancy and infection the only possible aetiologies. ${ }^{1}$ The feeding vessel sign, which consists of a
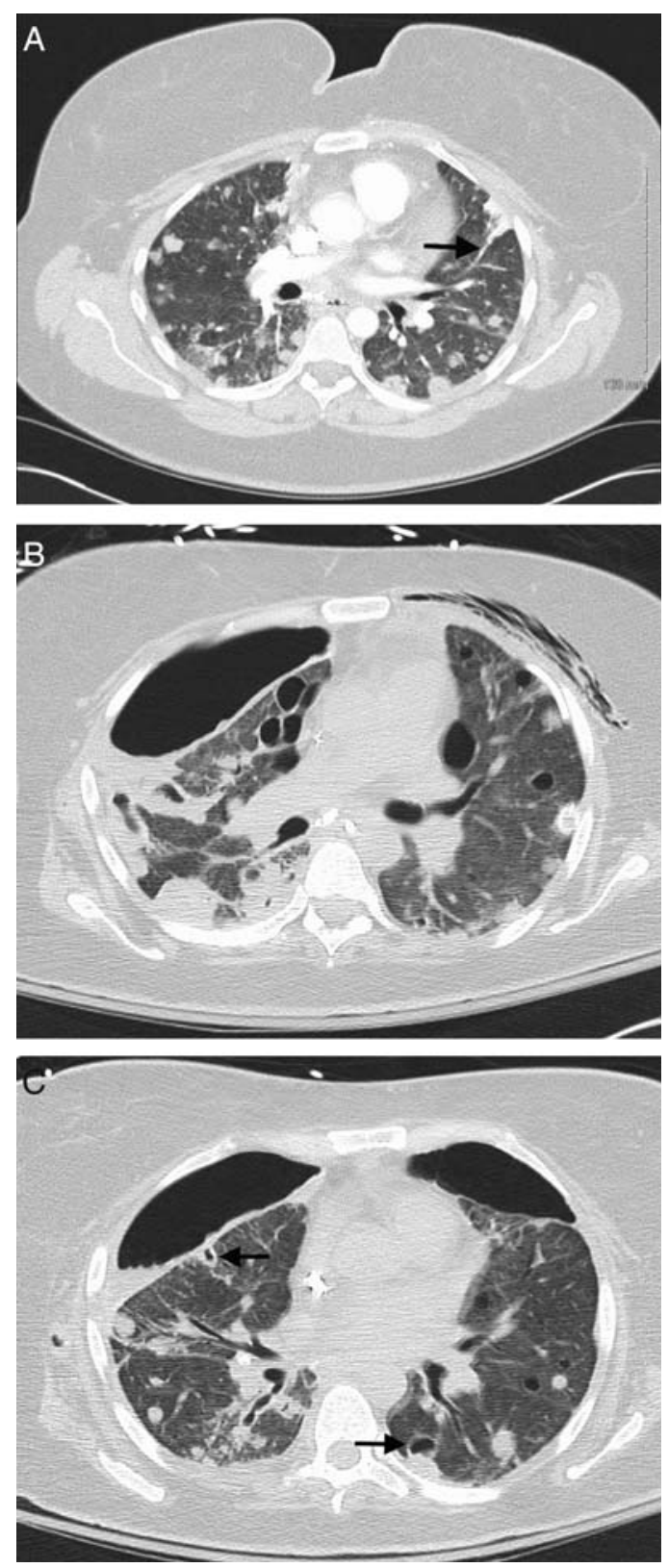

Figure $1 \mathrm{CT}$ of the chest on day 1 depicting diffuse pulmonary nodules in a random distribution with a feeding vessel sign (arrow) (A). CT of the chest on day 30 showing persistence of nodules with interval development of pneumothoraces (B). CT of the chest on day 50 showing improvement in the size and quantity of nodular lesions with scattered cavitation (arrows) (C).

distinct vessel leading directly to a nodule, has been considered highly suggestive of septic pulmonary embolism. Cavitation within the nodule is another finding that reflects local necrosis and infarction, 


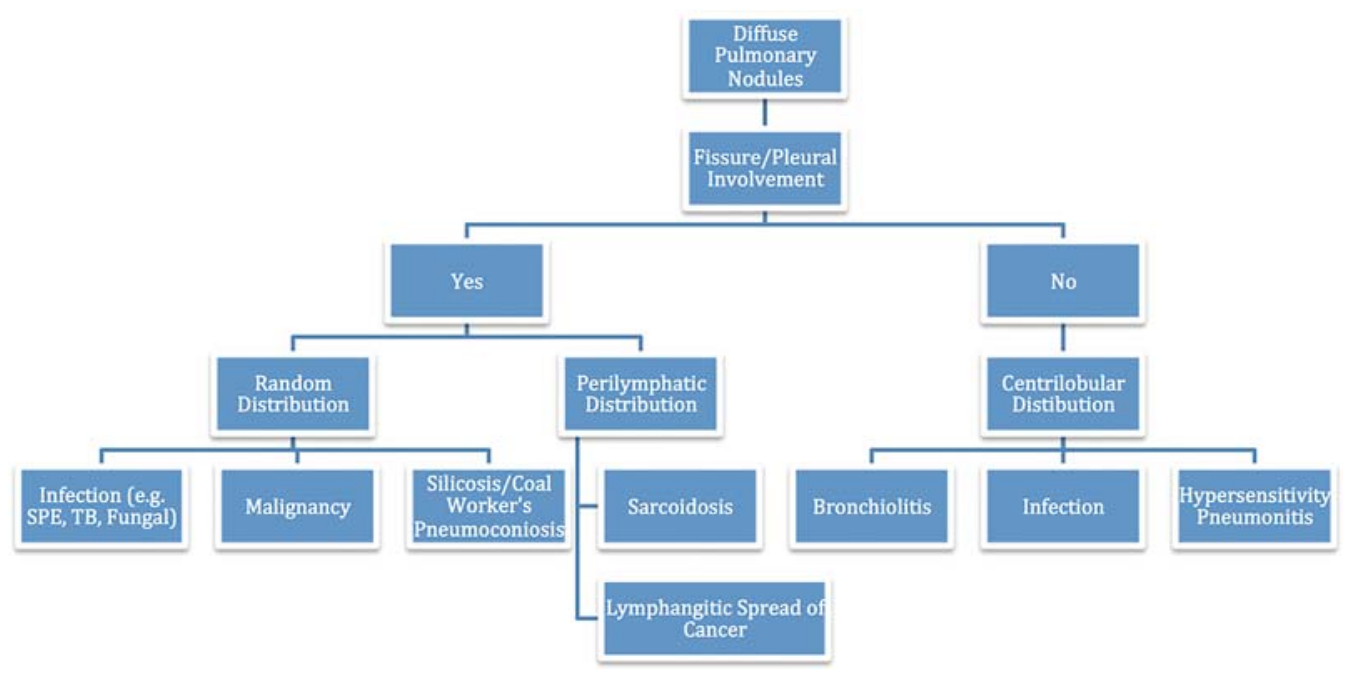

Figure 2 Chart depicting basic approach to the nodular pattern on chest imaging. SPE, septic pulmonary emboli; TB, tuberculosis.

and the development of pneumothoraces is a recognised complication associated with septic pulmonary emboli. All of which were seen in the patient. ${ }^{1}$

\section{Learning points}

- The differential diagnosis of diffuse pulmonary nodules should always include malignancy, but the unresolving nature should not deter physicians from a diagnosis of septic pulmonary emboli (SPE) in the proper clinical setting as these lesions can take up to 8 weeks to show signs of resolution.

- A basic approach that involves determining the distribution of diffuse pulmonary nodules can help narrow down the differential diagnosis, as shown in the figure.

- Random distribution, involvement of the pleurae, central necrosis and/or cavitation within nodules, and the feeding vessel sign, are all findings consistent with SPE.
The unusual finding was the unresolving nature of these infectious nodules in a patient with a history of cancer. The radiographic evolution of SPE has not been well described in the literature, and there is an expectation that infection should resolve rapidly. Levent $e t a l^{3}$ described a single case of SPE from septic arthritis in which nodular lesions showed marked improvement after 3 weeks of antibiotic therapy. The nodular lesions in the present case persisted up to 8 weeks until mild improvement was visualised (figure 1C).

Competing interests None.

Patient consent Obtained.

Provenance and peer review Not commissioned; externally peer reviewed.

\section{REFERENCES}

1 Cook RJ, Ashton RW, Aughenbaugh GL, et al. Septic pulmonary embolism: presenting features and clinical course of 14 patients. Chest 2005;128:162-6.

2 Boitsios G, Bankier AA, Eisenberg RL. Diffuse pulmonary nodules. AJR Am J Roentgenol 2010;194:W354-66.

3 Levent E, Sariman N, Soylu AC. The evolution of radiological lesions due to septic pulmonary embolism. Turk Thorac J 2011;12:39-43.

Copyright 2015 BMJ Publishing Group. All rights reserved. For permission to reuse any of this content visit

http://group.bmj.com/group/rights-licensing/permissions.

BMJ Case Report Fellows may re-use this article for personal use and teaching without any further permission.

Become a Fellow of BMJ Case Reports today and you can:

- Submit as many cases as you like

- Enjoy fast sympathetic peer review and rapid publication of accepted articles

- Access all the published articles

- Re-use any of the published material for personal use and teaching without further permission

For information on Institutional Fellowships contact consortiasales@bmjgroup.com

Visit casereports.bmj.com for more articles like this and to become a Fellow 